\title{
Vastgeklonken aan de Fyra
}

\author{
Een padafhankelijkheidsanalyse van de onvermijdelijke keuze voor de falende flitstrein
}

\section{Auteurs: Lasse Gerrits \& Peter Marks}

Leader: Met het terzijde stellen van de Fyra V250-treinen is een nieuwe wending bereikt in de twintig jaar dat Nederland probeert een hoge-snelheidslijn op de rails te krijgen. De logische vraag is wie er schuldig is aan dit dieptepunt. In dit artikel analyseren we de 20 jaar van besluitvorming aan de hand van de economische theorie over padafhankelijkheid in besluitvorming. Op basis van een uitgebreide inhoudsanalyse van meer dan 1200 documenten concluderen we dat, gegeven alle eerdere besluiten met betrekking tot o.a. de bouw en de concessieverlening, de keuze voor de V250 een noodgedwongen en onvermijdelijke gok was. Alle betrokkenen, van NS tot Tweede Kamer, blijken bij te dragen aan het vastlopen van dit project.

Abstract: In spring 2013, the Dutch railway operator High Speed Alliance cancelled the acceptance procedures for the V250 high-speed train sets they ordered from Italian manufacturer AnsaldoBreda after numerous problems with the build quality and safety systems. It is the latest chapter in a series of failing attempts to build and run a high-speed railway link between Amsterdam and Paris. Inevitably, the question of who was responsible for the decision to order the V250 has become prominent. We analyze 20 years of public decision-making by means of content analysis of over 1200 documents. Using David's and Arthur's theory of path-dependency, we conclude that all the decisions that were taken during those two decades created a situation in which the choice for the V250 was nothing more than an inevitable gamble. It can therefore be concluded that all parties involved, from the railway operator to the Parliament, have contributed to the current failure.

Keywords: complex decision-making, high-speed railways, megaprojects, path-dependency

1

Inleiding

Met het terzijdestellen van de V250 is het Nederlands hogesnelheidstreinproject in een nieuwe fase terechtgekomen. De betrokkenen geven elkaar de schuld van dit kostbare project, deels uit opportunisme, deels uit oprechte zorg over de gang van zaken. Het politieke spel is niet vrijblijvend. Achter de retoriek schuilt een reële schuldvraag, zowel in politieke als in juridische zin. In dit artikel betogen we dat beslissingen over de HSL-Zuid en de Fyra die op dat specifieke moment logisch en rationeel leken bij elkaar opgeteld op de lange termijn een situatie opleveren waarin actoren nauwelijks meer bewegingsvrijheid hebben en bepaalde keuzes door de situatie worden afgedwongen. Onze analyse is gegrond in de theorie over pad-afhankelijkheid. We zullen eerst kort uiteenzetten wat de kern van die theorie is. Daarna presenteren we de onderzoeksmethode, gevolgd door de analyse en onze conclusies over de onvermijdelijkheid van de keuze voor het aanbod van treinfabrikant AnsaldoBreda dat niet uitpakte zoals verwacht. 
De casus HSL-Zuid en Fyra-dossier zijn te kenschetsen als voorbeelden van complexe besluitvorming (bijv. Bekebrede en Van Bilsen, 2009: 26). Dergelijke complexiteit is met verschillende complexiteitsvriendelijke theorieën en methoden te analyseren (bijv. Teisman, 2005; Geyer \& Rihani, 2010; Gerrits, 2012; Morçöl, 2012). Voor dit onderzoek concentreren we ons op het mechanisme van pad-afhankelijkheid (bijv. Van den Bergh \& Gowdy, 2000).

Pad-afhankelijkheid vertrekt vanuit het algemene idee dat het verleden van invloed is op de huidige situatie en dat deze situatie kan worden begrepen door de historische paden te analyseren (Pierson, 2000). Eenmaal genomen beslissingen bepalen de condities voor de volgende stap op hetzelfde pad, waardoor de vrijheidsgraden voor afwijkende beslissingen afnemen gedurende de tijd (Wood 2001 in Pierson, 2006), bijvoorbeeld omdat de kosten die gemaakt moeten worden om over te stappen groter zijn dan de kosten om op de ingeslagen weg te blijven, zelfs als het alternatief wordt geprefereerd boven het huidige pad. Dit fenomeen werd door David voor het eerst beschreven en wordt lock-in genoemd (David, 1985; Arthur, 1994). Het ingeslagen pad kan bewust of onbewust gekozen zijn maar levert op de langere termijn een steeds minder flexibele situatie op waardoor besluitnemers door de omstandigheden zich gedwongen voelen door te gaan op de ingeslagen weg.

Dit generieke principe kent een aantal specifieke verklarende mechanismen. Stel dat besluitvormers een keuze moeten maken tussen twee concurrerende en elkaar uitsluitende alternatieven $(A$ en $B$ ) als oplossing voor een probleem. Als een bepaald alternatief meer gebruikers kent stijgt het rendement daarvan. Dit zelfversterkende mechanisme - ook wel 'positive feedback' genoemd - houdt in dat doordat een aantal gebruikers een bepaald alternatief gebruikt het voor de volgende gebruiker meerwaarde heeft om hetzelfde alternatief te gebruiken door de aansluiting met die andere gebruikers, ten opzichte van als eerste gebruiker te starten met het andere alternatief. Bijvoorbeeld: als het Ministerie kiest voor de ERMTS-standaard voor treinbeveiliging in plaats van voor ATB-NG, dan stijgt het rendement van deze technologie als andere landen en treinbedrijven ook die standaard gaan hanteren voor hun netwerk en treinen. Rendementen kunnen een monetaire vorm aannemen maar dat hoeft niet. ERMTS kan bijvoorbeeld ook de veiligheid en het reizigersgemak doen toenemen. Het verwachte rendement van de keuzes staat weergeven in onderstaande figuur.

\begin{tabular}{|l|l|l|l|l|l|l|l|l|l|l|l|}
\hline \# Gebruikers & 0 & 10 & 20 & 30 & 40 & 50 & 60 & 70 & 80 & 90 & 100 \\
\hline Alternatief $A$ & 10 & 11 & 12 & 13 & 14 & 15 & 16 & 17 & 18 & 19 & 20 \\
\hline Alternatief B & 7 & 9 & 11 & 13 & 15 & 17 & 19 & 21 & 23 & 25 & 27 \\
\hline
\end{tabular}

Figuur 1 - Verwachte rendementen van alternatieven

Besluitvormers zijn begrensd in hun rationaliteit (Simon, 1955; Bendor, Kumar \& Siegel, 2009) en weten dus niet goed wat een bepaald alternatief op de lange termijn gaat opleveren. Over het algemeen kiezen zij daarom eerder voor een hoger rendement op de korte termijn, ook wanneer_al dan niet bekend - dat op de lange termijn minder oplevert (David, 1985; Martignon, et al., 2003). Een complicerende factor is dat de keuze die op een bepaald moment moet worden gemaakt deels wordt ingegeven door de omstandigheden van dat specifieke beslismoment. Dat kunnen gebeurtenissen zijn als een toetredende actor die over meer kennis van een bepaald alternatief beschikt of media-aandacht over slechts één van de twee alternatieven waardoor sociale druk ontstaat. Een dergelijke voor de besluitvormers onvoorspelbare gebeurtenis is non-ergodisch (Durlauf 2005: 226), i.e. de gevolgen van de gebeurtenis blijven resoneren door de tijd heen omdat deze deels de basis vormen voor de genomen beslissing. Bijvoorbeeld: de klacht van Deutsche Bahn en Arriva in de Volkskrant (3-2-2001) dat de vervoersconcesssie voor de HSL te duur zou zijn was niet voorzien door de minister. De daaropvolgende tijdelijke schorsing betekende dat het consortium vitale informatie voor de bieding werd onthouden waardoor het op achterstand kwam in de biedingstrijd. 
Terug naar de hypothetische situatie in figuur 1; gegeven de begrensde rationaliteit zullen de eerste gebruikers voor alternatief $A$ kiezen. Hier gaat het zelfversterkende mechanisme werken aangezien wardoor het het-voor andere gebruikers aantrekkelijker wordten om ook voor dat alternatief te kiezen vanwege het hogere rendement. Op de langere termijn ontstaat er inflexibiliteit en een vast pad gebaseerd op alternatief $A$ (cf. Gerrits \& Marks, 2008). Als in het voorbeeld meer dan dertig gebruikers alternatief $A$ volgen is levert alternatief $B$ hoger bij eenzelfde hoeveelheid volgers een hoger rendement op. Echter de eerste dertig gebruikers die $A$ volgen zouden dan allemaal moeten overstappen naar alternatief $B$ om deze rendementen ook daadwerkelijk te kunnen verkrijgen; dit is een heel grote investering. Deze grote investering, ofwel verzonken kosten ${ }_{\llcorner}$in dit proces zorgen ervoor dat de overstap niet gemaakt zal worden ondanks dat men nu vastzit aan het lager renderende alternatief. $\mathrm{Er}$ is dan sprake van pad-afhankelijke inefficiëntie (Arthur, 1994). Achteraf kan bijvoorbeeld worden gesteld worden dat er betere alternatieven waren dan de V250 die door AnsaldoBreda werd aangeboden. Echter, deze keuzemogelijkheid is nu onbereikbaar zonder extreme overstapkosten. De bovengenoemde theoretische elementen 'onvoorspelbare gebeurtenissen', 'non-ergodiciteit', 'potentiële pad-afhankelijke inefficiëntie' en 'inflexibiliteit' vormen de kern van onze analyse.

\section{$3 \quad$ Methodologie}

Pad-afhankelijkheid kan met verschillende methoden worden onderzocht maar vereist altijd een longitudinale benadering. Voor dit onderzoek kiezen we voor een kwalitatieve analyse op basis van geschreven bronnen. Omdat de projectgeschiedenis teruggaat tot de jaren ' 80 zijn geschreven bronnen een goede basis om een helder beeld te krijgen van wat destijds de afwegingen en motieven voor bepaalde besluiten waren. Het vereist kwalitatieve data om die overwegingen te kennen en te begrijpen om vervolgens de elementen van pad-afhankelijkheid te kunnen identificeren.

Voor de analyse zijn 1256 documenten geselecteerd. Deze zijn onder te verdelen in de volgende categorieën: nieuwsberichten uit LexisNexis (1191); artikelen uit vakbladen (6); beleidsdocumenten van het Ministerie van Infrastructuur en Milieu (voorheen Verkeer en Waterstaat) en brieven aan de Tweede Kamer (28) en Tweede Kamerstukken, waaronder de evaluatierapporten van de Algemene Rekenkamer en de Tijdelijke Commissie Infrastructuurprojecten en hun onderliggende documenten(28). De documenten beslaan de periode van 28 april 1994 - voorjaar 2013. De volledige lijst met alle bronnen is beschikbaar bij de auteurs. Voor de nieuwsberichten vond datatriangulatie plaats door bronvergelijking. Dat leidde er bij uitzondering toe dat bepaalde berichten uit de analyse moesten worden gehaald omdat niet helder was of de weergave van de feiten correct was. Met een Event Sequence Database (ESD; Spekkink 2013) werden de nieuwsberichten gestructureerd in tijd en in drie samenhangende dossiers: (1) de openbare aanbesteding en de bouw van de HSL-Zuid; (2) de openbare aanbesteding en concessieverlening exploitatie van de HSL-Zuid; en (3) de aanbesteding van het nieuwe treinmaterieel en de pogingen om de treinen te gebruiken voor reguliere diensten op de HSL-Zuid. Voor elk dossier werd vastgelegd welke gebeurtenissen zich hebben voorgedaan, welke gevolgen die gebeurtenissen hadden en of deze gebeurtenissen gekoppeld waren aan gebeurtenissen in andere dossiers.

Deze dossiers, gestructureerd in de ESD, vormen de basis van de analyse. Vervolgens werden de gebeurtenissen verder uitgewerkt met behulp van de andere documenten om te reconstrueren welke overwegingen actoren hadden om een bepaald besluit te nemen of een andere actie te ondernemen, wat de risicoanalyses waren en welke toevallige omstandigheden werden betrokken in de | besluitvorming. Deze kwalitatieve data werd vervolgens gecodeerd voor de vier bovengenoemde theoretische elementen, i.e. in de teksten werd aangegeven waar welke elementen een rol speelden. Het coderen werd door beide auteurs gedaan waardoor interpretatieverschillen zichtbaar en opgelost konden worden. Deze grondige dataverwerking resulteerde in een reconstructie van de besluitvorming 
waarbij de elementen van pad-afhankelijkheid verklarende kracht hebben gekregen voor de ontstane situatie in zomer 2013.

De verwerking in ESD en codering zorgt voor een zeer gestructureerde en transparante dataverwerking. De methode kent ook nadelen. Inherent aan secundaire analyses is dat de interpretaties van de oorspronkelijke auteurs al zijn verwerkt in de weergave, waarbij zelfs triangulatie niet altijd toestaat interpretatieverschillen te ontdekken. Daarnaast mist op een aantal punten diepgaande informatie omdat deze eenvoudigweg niet toegankelijk is, zoals de precieze tekst van de tender voor de V250 treinen. We hebben getracht om met deze methode tot een zo zuiver mogelijke reconstructie te komen.

\section{4}

\section{De dossiers}

In deze sectie geven we de reconstructie van de besluitvorming weer. We zullen allereerst de achtergrond en de bouw van de HSL-Zuid schetsen om te bepalen wat de startcondities zijn waaronder de concessie wordt gegund. De concessieverlening en exploitatie zullen we gedetailleerder bespreken. Het eerste regeringsbesluit betreffende de aanleg van een hogesnelheidslijn werd genomen in 1979. Dit resulteert in haalbaarheidsstudies naar vier varianten in de jaren ' 80 . In juni 1990 wordt het regeringsbesluit genomen voor een aansluiting op het Europese hogesnelheidsnet van de Randstand naar het zuiden via een nieuw tracé. De afweging van verschillende tracé-varianten leidt tot de keuze van het A1-tracé door het Groene Hart.

\section{1}

\section{Dossier 1 (1994-2010) - Aanbesteding en bouw HSL-Zuid}

In de eerste fase worden door het Ministerie al veel beslissingen gemaakt die een definitief karakter hebben. Zo worden verschillende tracés en kunstwerken beoordeeld op de vraag of ze een maximum snelheid van $300 \mathrm{~km} / \mathrm{u}$, een korte reistijd en een maximum aan reizigers mogelijk maken. Het A1-tracé voldoet aan deze eisen. De beslissing het gehele tracé geschikt te maken voor die hoge snelheid lijkt flexibiliteit in te houden. Het snelheidsbereik is erg ruim waardoor verschillende exploitatiesnelheden kunnen worden aangehouden. In de praktijk wordt echter elke keuze over exploitatie en het benodigde materiaal gewogen aan de vraag of het de maximumsnelheid volledig benut omdat op deze manier de grote investeringen voor het snelle tracé zijn te rechtvaardigen. 'Tragere' varianten worden dan ook nauwelijks overwogen. In plaats van flexibiliteit wordt hier dus inflexibiliteit en daarmee potentiële padafhankelijke inefficiëntie verankerd.

Het besluit voor het A1-tracé kan in 1996 alleen politiek aanvaardbaar worden gemaakt door een gedeelte van het tracé te ondertunnelen, de zogeheten Groene Harttunnel. De extra kosten t.o.v. van de tunnelloze variant bedragen dan al 900 miljoen gulden. Dat bedrag tijdens de bouw nog verder oplopen. Toch zullen opeenvolgende kabinetten de keuze aanhouden ondanks verzoeken van de Tweede Kamer tot heroverweging. Het besluit om de tunnel te bouwen markeert een non-ergodisch moment: het werd op dat moment door het kabinet Kok I gezien als de enige mogelijkheid om consensus te bereiken gegeven de politieke verhoudingen maar de deels onvoorziene meerkosten drukken zo zwaar op het bouwbudget dat een tekort ontstaat dat het ministerie middels de concessie probeert terug te verdienen. Sommige andere beslissingen die op dat moment logisch leken gegeven de omstandigheden, denk aan het vervangen van de geluidschermen bij Breda, hebben hetzelfde effect.

Het streven om de meerkosten terug te verdienen wordt echter nog meer onder druk gezet doordat tijdens de bouw een aantal keer een groot kasritmeprobleem ontstaat. Daarnaast mislukt een volledige private financiering van de bouw - de wens van het kabinet - omdat belangstelling uit de 
markt in deze fase gering is. Moeizame en langdurige onderhandelingen zijn nodig waardoor een prijsopdrijvend mechanisme ontstaat. Tussentijdse aanpassingen van het ontwerp, zoals de pergola bij Hoogmade, of technische problemen door bijvoorbeeld verzakkingen bij Moerdijk zorgen voor uitstel en meerkosten. Hierdoor krijgen bepaalde projecten uitstel waardoor automatisch vertraging ontstaat voor het volgende aansluitende project. Gegeven het gekozen tracé leidden alle onvoorziene gebeurtenissen tot een continu bijstellen van het budget dat uiteindelijk verdubbelt naar $€ 11.8$ miljard t.o.v. de planologische kernbeslissing. Deze inflexibiliteit van het gekozen tracé is in potentie inefficiënt omdat gegeven de latere omstandigheden - zoals lagere reizigersaantallen ten opzichte van de prognoses het nauwelijks mogelijk is om andere exploitatievarianten, zoals andere routes, te ontwikkelen.

Tijdens de aanleg van de HSL-Zuid besluit de Europese Commissie dat bij nieuwe railprojecten een nieuwe Europese standaard voor treinbeveiliging moet worden ingevoerd, namelijk ERTMS. Het ministerie besluit in 2004 om ERTMS 2 exclusief in te voeren hoewel het dan nog niet uitontwikkeld is, in plaats van ERMTS 1 te hanteren of zelfs op het oude ATB te vertrouwen. Ook dit lijkt een toekomstbestendig besluit aangezien het nieuwste en meest geavanceerde systeem wordt gekozen, maar in de praktijk werkt het anders uit. Allereerst is het ministerie erg traag met haar beslissing vanwege moeizame onderhandelingen met leverancier Siemens. Ten tweede is er geen terugvaloptie mocht ERMTS 2 niet goed functioneren. Het trage besluit zorgt voor hogere kosten en een verder uitstel van de opleverdatum van zowel het tracé als treinen. Inflexibiliteit en potentiële inefficiëntie ontstaan omdat voor de exploitatie door het zelfversterkende mechanisme niet kan niet-worden teruggevallen op bestaand materieel aangezien dat niet geschikt is voor ERMTS, terwijl de HSL niet geschikt is voor het alom gebruikte ATB.

\subsection{Dossier 2 (1998-2007) - Concessie exploitatie}

De uitgangssituatie voor de gunning van de vervoersconcessie en de exploitatie is (1) dat het aantal keuzemogelijkheden is ingeperkt door eerdere beslissingen ten aanzien van o.a. de ontwerpsnelheid en het beveiligingssysteem, i.e. inflexibiliteit; en (2) dat de kosten van de aanleg en inpassing vele malen hoger liggen dan gepland, i.e. hoge verzonken kosten. De inflexibiliteit en potentiële inefficiëntie worden in dit dossier versterkt door de beslissing de verzonken kosten van de bouw te verdisconteren in de concessie. Deze uitgangssituatie is zeer bepalend voor de strijd rond de concessieverlening. De minister bevindt zich in een lastige positie. Enerzijds denkt ze dat een openbare aanbesteding zal leiden tot een biedingsstrijd tussen vervoerders en daarmee een hogere gebruikersvergoeding voor het ministerie. Anderzijds staat ze onder grote druk van de Tweede Kamer en NS om de concessie onderhands te gunnen aan de NS omdat deze actoren het idee van een buitenlandse vervoerder die de HSL-Zuid gaat exploiteren moeilijk kunnen verteren.

Tussen 1999 en 2000 geeft de minister NS herhaaldelijk de kans om de concessie binnen te halen maar de aanbiedingen worden door het ministerie beoordeeld als 'onder de maat', hetgeen, voor NS onverwacht, resulteert in de beslissing van 8 juni 2000 om toch over te gaan op een openbare besteding. In een toelichting op de aanbesteding maakt het kabinet aan de Tweede Kamer bekend dat de exploitatie ten minste $\mathbf{2} 20$ miljoen gulden per jaar moet gaan opleveren "omdat de aanleg van het Nederlandse deel van de HSL-Zuid veel duurder is geworden dan was voorzien." Tegelijkertijd houdt de minister de Tweede Kamer rustig door de tender zo op te stellen dat alleen NS als winnaar uit de strijd kan komen. De NS is daar echter niet gerust op en besluit vlak voor de deadline tot een bod van €160 miljoen per jaar, substantieel hoger dan de andere aanbiedingen. De NS wint daarmee de concessie maar het ministerie verlaagt na onderhandelingen met de NS de vergoeding naar €148.4 miljoen uit angst dat NS ten onder zou kunnen gaan aan het hoge bod. Naast een hoge vergoeding legt de NS zich ook contractueel vast op een zitplaatsgarantie van $98 \%$ en bepaalde maximum reistijden die door het 
ministerie worden bepaald. Deze vereisten bepalen de overgebleven bewegingsvrijheid omdat NS de hoge kosten voor de concessie tijdens de exploitatie zal moeten terugverdienen met treinen met voldoende capaciteit en die de vereiste reistijd behalen.

\subsection{Dossier 3 (2003-2013) - Aanbesteding en operatie V250.}

Ondanks allerlei gesteggel over de verdeling van de inkomsten en het wel of niet aandoen van Breda in de route wordt er tussen HSA, de exploitatiemaatschappij van NS en KLM voor de HSL-Zuid, en NMBS, de Belgische spoorvervoerder, een overeenkomst gesloten waarin de samenwerking op het NederlandsBelgische deel van het traject van de HSL-Zuid wordt omschreven. NMBS en HSA geven op 3 november 2003 per brief aan de minister aan van zins te zijn treinen te bestellen met een maximumsnelheid van 220 kilometer per uur om de kosten laag te houden. Een TGV of ICE die $300 \mathrm{~km} / \mathrm{u}$ rijdt zou ongeveer twee keer zo duur zijn maar slechts een minimiememinieme tijdwinst opleveren. Vervolgens wordt in 2002 de aanbestedingsprocedure voor de treinen gestart waarbij het belangrijkste gunningscriterium de 'prijs per volwaardige zitplaats' is. Daarnaast moet het materieel geschikt zijn voor ERMTS 2, dan nog steeds in experimentele fase, en moet het van NS een spraakmakend uiterlijk krijgen vanwege marketingoverwegingen.

De tender resulteert in het voorjaar van 2003 in vier aanbiedingen van Alstom, Siemens, BN (later Bombardier) en AnsaldoBreda. Drie aanbiedingen betreffen aangepast standaardmaterieel, zoals een getrokken dubbeldekstrein van Alstom. Het ministerie bepaalt dat met $220 \mathrm{~km} / \mathrm{u}$ de gecontracteerde rijtijd niet haalbaar is en eist dat HSA zich aan het contract houdt, inclusief de zitgarantie. Deze inflexibiliteit van het ministerie zorgt er voor HSA onverwachts voor dat Bombardier en Siemens zich terugtrekken. Siemens, bijvoorbeeld, wil voor een dergelijke kleine order geen capaciteit vrijmaken om hun ICE-treinen aan te passen aan de eisen. Vlak voor het sluiten van de tender trekt ook Alstom zich terug omdat ze schatten dat ze geen aantrekkelijke business case kunnen opstellen gegeven de eisen. AnsaldoBreda daarentegen biedt op dat laatste moment een variant aan die $250 \mathrm{~km} / \mathrm{u}$ kan en slechts marginaal duurder zou zijn dan hun eerdere aanbod, de 230-variant. Zo is voorjaar 2004 AnsaldoBreda de enige aanbieder die voldoet aan alle Europese aanbestedingsregels en een product kan aanbieden dat aan alle eisen voldoet - op papier althans, de V250 is vooralsnog niet meer dan een ontwerp. Inefficiëntie in de gekozen methode voor de bouw wordt nu zichtbaar doordat de HSL-Zuid geschikt is gemaakt voor $300 \mathrm{~km} / \mathrm{u}$. Hierdoor werd de constructie duurder terwijl materieel dat 250 $\mathrm{km} / \mathrm{u}$ volstaat voor de gewenste reistijden.

Al snel blijkt dat het ontwerpen en bouwen van nieuw materieel AnsaldoBreda maar moeizaam afgaat. Er is dan ook geen V250 beschikbaar wanneer de exploitatie van start gaat. Het ministerie en HSA ruziën vervolgens over de oplossing, o.a. waar vervangende treinen geleased kunnen worden en wie voor de kosten opdraait. Ondertussen moet in alle HSL-materiaal, de Thalys en de vervanging van de V250, het al eerder besproken nieuwe veiligheidssysteem ERTMS komen. HSA wil als back-up een bestaand beveiligingssysteem inbouwen zodat het minder afhankelijk is van ERMTS 2 dat nog niet beproefd is. Het ministerie geeft echter geen toestemming uit vrees dat parallelle systemen het treinverkeer mogelijk minder betrouwbaar maken. Door deze discussie loopt de levering van het materieel verdere vertraging op maar de minister wil HSA aan de oorspronkelijke deadlines houden. De in dossier ontstane inflexibiliteit van ERMTS resoneert dan dus niet alleen door in de aanleg van de HSL, maar ook in de levering en aanpassing van alle HSL-materieel. Om toch met de exploitatie te kunnen beginnen worden getrokken treinen geleased die $160 \mathrm{~km} / \mathrm{u}$ halen, onder de merknaam Fyra.

In juli 2009 wordt het prototype van de V250 gepresenteerd. Door alle vertragingen is HSA echter in grote financiële problemen gekomen want het betaalt wel voor de concessie maar kan nog steeds niet beginnen met de volwaardige exploitatie. De minister verleent vier jaar uitstel van betaling. 
De geïmproviseerde Fyra blijkt echter met geen mogelijkheid succesvol te worden, zelfs tariefbijstellingen en toeslagenreducties helpen niet. Dan worden de financiële problemen bij HSA zo groot dat de minister hen andermaal moet redden met een aangepaste concessie tegen $€ 101$ miljoen per jaar waarbij de HSL onderdeel wordt van het hoofdrailnet en NS garant staat voor HSA. Op 9 december 2012 wordt eindelijk de eerste V250 in passagiersdienst ingezet. Onmiddellijk komen veel gebreken aan het licht: terugkerende problemen met het beveiligingssysteem en veel constructiefouten. $\mathrm{Na}$ een sneeuwperiode met uitzonderlijk veel materieeluitval wordt de trein al weer uit dienst genomen. In het voorjaar 2013 blijkt uit een technisch rapport dat er zo veel mis met de trein dat NMBS en NS de treinen definitief terzijde stellen en NS het koopcontract met AnsaldoBreda formeel op 30 augustus 2013 opzegt.

\section{5}

\section{Conclusies en discussie}

De reconstructie laat zien dat alle actoren op verschillende momenten in de tijd op verschillende | manieren geconfronteerd is-zijn geweest met beslissingen uit het verleden die de bewegingsruimte op het gegeven beslismoment sterk beperken. Over de drie dossiers bekeken tekent de pad-afhankelijkheid zich duidelijk af. De kiem wordt gelegd tijdens de bouw en de non-ergodische beslissingen en gebeurtenissen die daar plaatsvinden die een zelfversterkende effect hadden. Het pad wordt versterkt en daarmee nog minder flexibel tijdens de aanbesteding en gunning van de exploitatie, om uiteindelijk uit te monden in de lock-in van de V250. De optelsom van alle door begrensde rationaliteit en door toevallige omstandigheden ingegeven beslissingen sinds het eerste tracébesluit tot en met de eisen van de concessieverlening zorgen ervoor dat de V250 van AnsaldoBreda de enige overgebleven mogelijkheid vormde voor HSA om zichzelf te redden omdat de inspanningen om over te stappen op een alternatieve route nog groter zouden zijn dan doorgaan op de ingeslagen weg.

Als de kosten van de bouw van de HSL-Zuid niet exponentieel waren gestegen had minder terugverdiend hoeven te worden in de concessie. De concessie werd nog duurder doordat NS veel hoger bood dan op basis van de verwachte exploitatie te verantwoorden was uit angst de monopoliepositie te verliezen. Deze omstandigheden vielen samen met de eisen van het ministerie aangaande de exploitatie en het materieel en dus de selectie van AnsaldoBreda. Het eindresultaat is inefficiëntie zoals zichtbaar in het feit dat er geen volwaardige exploitatie-alternatieven bleken te zijn toen de levering van de V250 vertraagd werd en uiteindelijk niet geschikt bleek voor reguliere diensten.

De politieke en juridische schuldvraag moet nog beantwoord worden. Onze analyse laat zien dat de oorzaak van het huidige debacle te vinden is in het gehele complex van besluiten die door alle betrokkenen zijn genomen in de afgelopen twintig jaar. De Tweede Kamer heeft net zo goed bijgedragen aan de huidige situatie als bijvoorbeeld het ministerie en de NS. Het streven om met de HSL-Zuid een Europese koploper aan te leggen en daarom te kiezen voor experimentele techniek en nieuwe manieren van ontwikkeling door o.a. openbare aanbesteding en PPS komt als een boemerang terug in de vorm van substantiële kostenoverschrijdingen, niet-functionerende hardware en een onrendabele exploitatie. Het is politiek gezien mogelijk de huidige bewindsvoerder verantwoordelijk te stellen maar als één ding duidelijk is in dit langlopende project, dan is het wel dat de meeste bewindvoerders bijkans niet meer waren dan een doorgeefluik voor slecht nieuws over de HSL. De ironie van de situatie is overigens dat het reparatieplan voor de toekomstige exploitatie, zoals voorgesteld tijdens de zitting van de vaste Kamercommissie sterk lijkt op het IntercityMax-plan dat de NS eind 1999 indiende bij het ministerie in een poging de concessie voor de HSL in handen te krijgen.

Tot slot een theoretische reflectie. Het analyseren van de pad-afhankelijkheid die optreedt in besluitvorming legt de focus op het zelfversterkende mechanisme door toenemende gebruikers waardoor de de afnemende-flexibiliteit afneemt ten opzichte van de startcondities zoals ervaren door 
actoren. Hoewel mag worden aangenomen dat veel besluiten per definitie de potentie van padafhankelijkheid in zich dragen kan het vaststellen van een daadwerkelijke lock-in alleen retrospectief gebeuren. Daarmee behoort pad-afhankelijkheid tot de groep reconstructietheorieën uit de bestuurskunde (cf. Kalders, 1999). Pad-afhankelijkheid is een van de elementen die er voor zorgen dat collectieve besluitvorming zo complex kan zijn. Door dergelijke mechanismen bloot te leggen kunnen we steeds beter begrijpen waarom het zo moeilijk kan zijn om grote projecten tot een goed einde te brengen

De auteurs danken Warda Belabas voor haar assistentie tijdens de dataverzameling.

Dit onderzoek werd mede-gefinancieerd door NWO Veni-beurs, no. 451-10-022
Comment [LG1]: Dit stukje in antwoord op reviewer 2 over besluitvormingsmodellen.

\section{Literatuurlijst}

Arthur, W.B. (1994). Increasing returns and path-depedence in the economy. Ann Arbor: The University of Michigan Press.

Bekebrede, G. en A. van Bilsen (2009). Spelen met complexiteit: serious gaming voor besluitvorming over ruimtelijke infrastructuren. Bestuurskunde 18(3): 24-35.

Bendor, J. B., Kumar, S., \& Siegel, D. A. (2009). Satisfying: A 'pretty good' heuristic. The BE Journal of Theoretical Economics, 9(1): 1-36.

Bergh, J.C.J.M. van den \& Gowdy, J.M. (2000). Evolutionary theories in environmental and resource economics: Approaches and applications. Environmental and Resource Economics 17: 37-57.

David, P.A. (1985). Clio and the economics of QWERTY. The American Economic Review 75(2): 332-337.

Durlauf, S.N. (2005). Complexity and empirical economics. The Economic Journal 115: 225-243.

Gerrits, L.M. en P.K. Marks (2008). Complex bounded rationality in dyke construction: Path dependency and lock-in in the emergence of the geometry of the Zeeland delta. Land Use Policy 25(3): 330337.

Gerrits, L.M. (2012). Punching clouds: An introduction to the complexity of public decision-making. Litchfield Park: Emergent Publication.

Martignon, L., Vitouch, O., Takezawa, M., \& Forster, M. R. (2003). Naive and yet enlightened: From natural frequencies to fast and frugal decision trees. In D. Hardman, \& L. Macchi (Eds.), Thinking: Psychological perspectives on reasoning, judgment and decision making (pp. 189-211). Chichester: Wiley Online Library.

Morçöl, G. (2012). A complexity theory for public policy. New York: Routledge.

Pierson, P. (2000). Increasing returns, path dependence, and the study of politics. American political science review, 251-267.

Pierson, C. (2006). Beyond the welfare state? The new political economy of welfare. Cambridge: Polity Press.

Reed, M. \& D.L. Harvey (1992). The new science and the old: Complexity and realism in the social sciences. Journal for the Theory of Social Behavior 22(4): 353-380.

Simon, H.A. (1955). A behavioral mode of rational choice, Quarterly Journal of Economics 69(1): 99-188.

Spekkink, W. (2013). Institutional capacity building for industrial symbiosis in the Canal Zone of Zeeland in the Netherlands: a process analysis. Journal of Cleaner Production, vol. 52(1): 342-355 
Teisman, G. R. (2005). Publiek management op de grens van chaos en orde: Over leidinggeven en organiseren in complexiteit. Den Haag: Sdu Uitgevers.

Tweede Kamer (2004). Onderzoek naar infrastructuurprojecten. Den Haag: Sdu Uitgevers.

Over de auteurs:

Dr. Lasse Gerrits

Universitair Hoofddocent Bestuurskunde

Erasmus Universiteit Rotterdam

Afdeling Bestuurskunde, kamer M8-37

Burgemeester Oudlaan 50

3000 DR Rotterdam

gerrits@fsw.eur.nl

Dr. Peter Marks

Universitair Docent Bestuurskunde

Erasmus Universiteit Rotterdam

Afdeling Bestuurskunde, kamer M8-39

Burgemeester Oudlaan 50

3000 DR Rotterdam

marks@fsw.eur.nl 